\title{
Liberalização Comercial e Estruturas de Emprego e Salário*
}

\author{
Jorge Saba Arbache** \\ Carlos Henrique Corseuil ${ }^{* * *}$
}

Sumário: 1. Introdução; 2. Liberalização Comercial e Estruturas de Emprego e Salário; 3. Estratégia Empírica; 4. Resultados; 5. Conclusões.

Palavras-chave: liberalização comercial; estrutura de emprego; estrutura de salário; Brasil.

Códigos JEL: F16; J21; J31.

Este artigo investiga se a liberalização comercial introduzida no Brasil em fins da década de 1980 afetou as estruturas de emprego e salários. Analisaram-se os dados da indústria manufatureira entre 1987 e 1998, período pré e pós-abertura, e encontraram-se evidências de que tanto a diminuição das tarifas de importação como o aumento dos fluxos comerciais pouco mudaram a participação relativa do emprego e os prêmios salariais inter-industriais. Mostra-se que esses resultados estão associados à elevadíssima estabilidade das estruturas de emprego e salários no Brasil.

This article investigates whether the trade liberalization introduced in Brazil by the end of the 1980s and beginning of the 1990s affected the structure of employment and wages. We use manufacturing sector data from 1987 to 1998 and found evidence that neither the decrease of import tariffs nor the higher trade flow affected the employment shares and inter-industry wage premia. We show that these results are due to the very high stability of employment shares and relative wages.

\footnotetext{
*Artigo recebido em dez. 2000 e aprovado em dez. 2003. Gostaríamos de agradecer os comentários e sugestões de dois pareceristas anônimos, a Wilson Menezes e aos participantes do Encontro da ANPEC de 2000 e do Workshop de Economia do Trabalho e Bem-Estar da PUC-Rio. Os erros e omissões são, naturalmente, nossos. Arbache foi financiado pelo Conselho Nacional de Desenvolvimento Científico e Tecnológico $(\mathrm{CNPq})$, a quem gostaria de agradecer.

** Universidade de Brasília. Email: jarbache@unb.br

${ }^{* * *}$ Instituto de Pesquisa Econômica Aplicada.
} 


\section{Introdução}

No final dos anos 80 foi introduzida uma ampla reforma na política comercial brasileira após várias décadas em que o comércio exterior foi empregado como um dos principais instrumentos para garantir a estratégia de industrialização por substituição de importações. Em poucos anos removeu-se um enorme e complexo sistema de proteção não tarifária, e reduziu-se as tarifas nominais e efetivas modais para cerca de $\frac{1}{4}$ daquela prevalecente na década de 1980. Os efeitos dessa reforma não tardaram e em consonância com a valorização cambial, já no início da década de 1990 houve mudança na tendência de queda das importações verificada ao longo dos anos 80. A penetração de importações na indústria manufatureira, setor mais afetado pela reforma, duplicou em apenas cinco anos, saltando de 5,5\%, em 1990, para $10,7 \%$, em $1995 .^{1}$

A partir das predições dos teoremas de Heckscher e Ohlin e Stolper e Samuelson, pode-se esperar que mudanças em políticas comerciais, como a experimentada pelo Brasil, tenham potenciais impactos na alocação setorial do emprego e nos salários relativos, respectivamente e, conseqüentemente, mudanças nas estruturas de emprego e salários inter-industriais. Num país em desenvolvimento, setores cujas tecnologias são intensivas em trabalho pouco qualificado devem observar crescimento da participação no emprego, enquanto setores intensivos em trabalho qualificado devem perder participação no emprego devido à suposta perda de competitividade no período pós-abertura. De outro lado, os salários relativos dos trabalhadores dos setores que experimentam maior concorrência externa devem diminuir, enquanto os salários relativos dos trabalhadores dos setores que ganham espaço devem aumentar.

Este artigo tem como objetivo investigar se a abertura comercial alterou as estruturas de emprego e salários industriais no Brasil. Examinar o caso do Brasil pode ser particularmente interessante por pelo menos três razões. Primeira, a desigualdade salarial no Brasil encontra-se entre as mais elevadas do mundo (Li et alii, 1998). Se a maior competição alterar a demanda relativa por fatores de produção em favor da mão-de-obra pouco qualificada, então dever-se-á observar redução da desigualdade salarial no país. Segunda, a liberalização comercial envolveu ampla remoção de proteção tarifária e, especialmente, não tarifária, e foi introduzida num período relativamente curto de tempo. Na medida em que tal reforma se seguiu à décadas de política de industrialização por substituição de importações, que teria provocado potenciais distorções alocativas e influenciado adversamente a formação dos preços, então pode-se esperar que a abertura tenha causado mu-

\footnotetext{
${ }^{1}$ Para maiores detalhes sobre a abertura comercial no Brasil, ver Kume et alii (2003).
} 
danças não desprezíveis nas estruturas de emprego e salários. Terceira, dadas as características da economia brasileira, o conhecimento da sua experiência pode contribuir para o entendimento das experiências de outros países com economias em estágios similares de desenvolvimento que introduziram reformas semelhantes.

Para se examinar a questão acima, investigam-se empiricamente os efeitos de variáveis de abertura nas estruturas de emprego e salários. Para tanto, estimaramse modelos em painéis com dados ao nível da indústria para o período que cobre as fases pré- e pós-abertura. O texto está organizado como segue. A seção 2 apresenta brevemente a relação entre abertura comercial e estruturas de emprego e salário. A seção 3 discute a estratégia empírica. A seção 4 apresenta a base de dados e os resultados econométricos. A seção 5 conclui.

\section{Liberalização Comercial e Estruturas de Emprego e Salário ${ }^{2}$}

O teorema de Heckscher e Ohlin estabelece o princípio de que um país tem vantagem comparativa na produção de bens intensivos no fator de produção mais abundante, já que tal fator seria relativamente mais barato se comparado ao preço do outro fator, que seria escasso. Um país que introduz reformas comerciais liberalizantes deve observar aumento da produção dos bens intensivos em fatores de produção abundantes, alterando, assim, a estrutura de emprego no país.

O teorema de Stolper e Samuelson foi a primeira formulação teórica a explicar a relação entre livre comércio e distribuição de renda entre os fatores de produção. Um resultado básico do teorema é que protecionismo aumenta os retornos do fator de produção escasso nos países em desenvolvimento, que são abundantes em mãode-obra, e o contrário deve ocorrer nos países desenvolvidos, que são abundantes em capital. Dessa forma, dever-se-á observar mudanças na estrutura de salários de um país que introduz abertura comercial.

$\mathrm{Na}$ abordagem acima, considera-se que tanto os preços dos produtos como a tecnologia são dados, o que não é necessariamente o caso, já que a formação dos preços em uma economia fechada pode divergir daquela de uma economia aberta, e a tecnologia de produção pode se alterar em decorrência de um processo de abertura comercial. Uma empresa que atuava em um mercado fechado extraindo rendas de monopólio terá que ajustar seus preços para aquele do mercado internacional uma vez que a economia se abre. Nessas condições, é esperado que a firma responda ao aumento da competição reduzindo custos, o que, por sua vez, pode levar à reduções dos prêmios salariais incorporados pelos trabalhadores através de

\footnotetext{
${ }^{2}$ Para maiores detalhes teóricos e metodológicos dessa literatura, ver Arbache (2002).
} 
barganha salarial. Esse movimento deve alterar a estrutura salarial. A estrutura de emprego também poderá ser alterada se firmas ou setores antes protegidos não puderem fazer frente à concorrência internacional experimentando, então, encolhimento.

No que diz respeito à tecnologia, a remoção de barreiras à importação aliada à maior competição internacional no mercado doméstico pode levar as firmas locais a adquirirem novas máquinas e equipamentos como meio de tornarem-se competitivas. Se as novas máquinas e equipamentos trazem embutidas tecnologias mais avançadas, então poderá haver alteração da demanda de trabalho por grau de qualificação, afetando, pois, a estrutura de salários e emprego. ${ }^{3}$ Esse caso é, talvez, particularmente aplicável para países em fase intermediária de desenvolvimento, como Brasil, Argentina, Chile e México.

A entrada de países como China, Índia, Bangladesh, Paquistão e Indonésia no mercado mundial de bens de elevado conteúdo de trabalho não qualificado em meados dos anos 80 teria alterado a estrutura de oferta de bens no mercado mundial reduzindo os preços e o retorno dos fatores envolvidos na produção de bens intensivos nesse setor. Esse movimento teria prejudicado países que tinham alguma vantagem comparativa na produção de bens intensivos em trabalho não qualificado. Como conseqüência, esses países seriam pressionados a mudar a estrutura de produção em busca de vantagem comparativa na produção de bens com conteúdo de trabalho de qualificação intermediária, resultando no aumento da demanda desses trabalhadores e na mudança da estrutura de salários. ${ }^{4}$

A literatura empírica internacional mostra que parece existir relação entre abertura, emprego e salários. Currie e Harrison (1997) e Márquez e Pagés (1997) encontraram pouco efeito da liberalização comercial no nível e crescimento do emprego. O primeiro trabalho investiga o Marrocos, enquanto o segundo investiga dezoito países latino-americanos. Já Rama (1994) encontrou, para o Uruguai, que a liberalização comercial teve significativo efeito no nível de emprego da manufatura. Hanson e Harrison (1999) e Harrison e Hanson (1999) encontram pouco ou nenhum efeito de tarifas sobre emprego e salários para o México e Marrocos. Revenga (1997) encontrou para o México que o ajustamento à liberalização comercial se deu mais nos salários dos trabalhadores dos setores que mais se beneficiavam com a economia protegida, e menos no nível de emprego. Rama (1994), por outro

\footnotetext{
${ }^{3}$ Esse ponto foi originalmente proposto por Robbins (1996), que o batizou de Skill EnhancingTrade Hypothesis.

${ }^{4}$ Esse argumento se deve a Wood (1999). Davis (1996) apresenta um modelo cuja principal hipótese é que a disponibilidade de fatores de produção de um país deve ser tomada não pela sua oferta a nível global, mas sim em relação a um limitado conjunto de países com dotações de fatores similares.
} 
lado, encontra limitado impacto da abertura nos salários do Uruguai.

A literatura para os países desenvolvidos apresenta resultados mais homogêneos. Grossman (1987) e Larre (1995) encontram baixa elasticidade dos salários e elevada elasticidade do emprego às medidas de abertura (tarifas e penetração de importações, respectivamente). Freeman e Katz (1991), Revenga (1992) e Gaston e Trefler (1993) encontraram efeitos significativos do aumento das importações e redução da proteção nominal tanto na alocação do emprego como nos salários relativos.

No caso do Brasil, há elementos para se supor que as estruturas de emprego e de salários tenham sido afetadas pela abertura. Arbache et alii (2004b) encontram que os salários das indústrias que tiveram maior exposição à abertura experimentaram queda proporcionalmente maior do seu valor relativo ao longo da década de 1990, e que os salários dos setores comercializáveis em geral foram mais afetados pela competição internacional que os salários dos setores não comercializáveis, afetando potencialmente a estrutura de salários industriais. Arbache (1999) e Menezes e Arbache (2002) identificaram relação inversa entre prêmios salariais inter-industriais e penetração de importação. Hay (2001) mostra que as margens de lucro na indústria manufatureira caíram na década de 1990, mas de forma mais acentuada nos setores mais expostos à abertura. Green et alii (2001) e Maia (2001) encontram, respectivamente, que os salários relativos dos trabalhadores mais qualificados aumentaram após a abertura vis-à-vis os salários dos trabalhadores menos qualificados, e que o aumento das importações e da produtividade destruíram mais postos de trabalho dos trabalhadores não qualificados que dos trabalhadores qualificados. Salm et alii (1997) e Chamon (1998) mostram que o ambiente mais competitivo induziu à adoção de novas técnicas produtivas e provocou substanciais investimentos em máquinas e equipamentos. Rossi e Ferreira (1999) encontram que a elevação das importações levou ao aumentou da produtividade total dos fatores. Esses resultados afetam potencialmente o mercado de trabalho, ao menos no curto prazo, e sugerem que as estruturas de emprego e salários teriam sido alteradas em razão da abertura.

\section{Estratégia Empírica}

Para identificar possíveis efeitos da liberalização comercial nas estruturas de emprego e salário da indústria manufatureira, estimaram-se painéis com dados do período de 1987 a 1998, o qual cobre as fases pré e pós-abertura. Modelos de efeitos fixos foram estimados para se contabilizar os impactos de variáveis omitidas específicas das indústrias, como tecnologia e composição, por exemplo. Se 
trabalhadores mais qualificados encontram-se nas indústrias mais produtivas, e se essa composição muda ao longo do tempo, então a inclusão de efeitos fixos tratará adequadamente os dados. Para minorar os eventuais efeitos de outras reformas simultâneas à abertura, como desregulamentação de mercados e privatização, nas estruturas de emprego e salários, os painéis foram estimados com time dummies.

Se encontrarmos que as relações entre variáveis dependentes - estruturas de emprego e de salários - e proxies de liberalização comercial diminuem ou mesmo desaparecem ante à inclusão de efeitos fixos no modelo, então poder-se-á concluir que não teria havido mudanças nas estruturas daquelas variáveis. Do contrário, se as relações forem robustas à inclusão de efeitos fixos, então poder-se-á concluir que teriam havido mudanças nas estruturas de emprego e/ou salários. Modelos de efeitos fixos com time dummies podem ser especialmente adequados para o caso brasileiro, em que as políticas comercial e cambial foram fortemente utilizadas como instrumentos de estabilização de preços ao longo do período em análise.

As variáveis dependentes do modelo são participação da indústria $j$ no emprego total e prêmio salarial inter-industrial controlado. Os modelos estimados partem da seguinte especificação básica:

$$
Y_{j t}=\alpha_{j}+\beta A_{j t}+\psi_{t}+u_{j t}
$$

onde:

$Y_{j t}$ representa as estruturas de emprego ou prêmios salariais;

$\alpha_{j}$ o efeito fixo referente à indústria $j$;

$A_{j t}$ as variáveis de abertura;

$\psi_{t}$ time dummies referente ao ano $t$; e $u_{j t}$ os erros.

A metodologia utilizada para estimar os prêmios salariais é a de HaiskenDeNew e Schmidt (1997), que corrige e refina o método desenvolvido e popularizado por Krueger e Summers (1988). As equações de salário foram estimadas da seguinte forma:

$$
\ln w_{i j}=\alpha+\beta X_{i}+\varphi Z_{j}+\epsilon_{i j}
$$

onde:

$\ln w_{i j}$ é o logaritmo natural do salário real por hora do trabalhador $i$ na indústria $j$

$X_{i}$ é o vetor de características pessoas, região geográfica, dentre outras variáveis de controle,

$Z_{j}$ é o vetor de dummies industriais, o qual inclui todas as indústrias, 
$\alpha$ é o intercepto, $\epsilon_{i j}$ é o distúrbio randômico refletindo as características não observáveis inerentes às estatísticas de salários,

$\beta$ e $\varphi$ são os vetores dos parâmetros a serem estimados. Como todas as dummies de indústria são incluídas no modelo, impõe-se uma restrição linear $\varphi$ da seguinte forma:

$$
\sum_{j} \varphi_{j} n_{j}=0
$$

onde $n_{j}$ é a participação no emprego da indústria $j$. Os coeficientes reportados são interpretados como a diferença proporcional do salário de um trabalhador da indústria $j$ e o trabalhador médio representativo de todo o conjunto de indústrias em análise. A formulação dada por (2) e (3) fornece, numa única etapa, coeficientes diretamente interpretáveis e com erros-padrão corretos. ${ }^{5}$

O cálculo da participação do emprego industrial e a estimação do prêmio salarial inter-industrial foram feitos a partir dos dados da Pesquisa Nacional por Amostras de Domicílio (PNAD), do Instituto Brasileiro de Geografia e Estatística. Os controles utilizados nas equações de salário foram escolaridade, experiência, experiência ao quadrado, gênero, raça, região geográfica, status do contrato de trabalho (com e sem carteira), chefe de família, urbano/rural e região metropolitana. Os filtros utilizados para a seleção dos dados foram trabalhadores entre 18 e 65 anos com salário positivo no emprego principal.

A grande vantagem dos prêmios salariais controlados em relação aos salários médios industriais é que aqueles refletem os efeitos específicos associados à filiação industrial na formação dos salários, como a estrutura de mercado e poder de barganha, o que não acontece com os salários médios. A estratégia metodológica adotada permite que eventuais mudanças induzidas pela liberalização comercial sobre a composição da qualificação da mão-de-obra sejam diretamente consideradas nas estimações evitando, assim, os potenciais viéses e endogeneidades normalmente encontrados em artigos dessa literatura (ver, por exemplo, Larre (1995); Revenga (1992, 1997); Currie e Harrison (1997), inter alia).

A investigação usou dois grupos de variáveis exógenas: medidas de política comercial, as quais são representadas por tarifas nominais e efetivas, e medidas de fluxo de comércio, representadas por penetração de importação e intensidade de exportação. As tarifas nominal e efetiva são de Kume et alii (2003). Penetração de importações e intensidade de exportações foram calculados, respectivamente, da seguinte forma: $M_{j} /\left(Y_{j}-X_{j}+M_{j}\right)$ e $X_{j} / Y_{j}$, onde $M$ é importação, $Y$ é produção,

\footnotetext{
$(2)$.

${ }^{5} \mathrm{Em}(1)$, a estrutura de salários representado por $Y_{j t}$ é dado pelo $\varphi$ estimado pela equação
} 
e $X$ é exportação da industria $j$. Os cálculos foram feitos a partir dos dados de Haguenauer et alii (1998).

Embora a literatura tipicamente empregue tarifas em análises de abertura comercial, aqui analisa-se, adicionalmente, variáveis de fluxo comercial, já que elas são capazes de ilustrar mais diretamente os efeitos das mudanças das políticas comerciais na alocação de fatores. ${ }^{6}$ Os modelos estimados não incluíram câmbio, o que pode superestimar os efeitos das medidas de proteção sobre emprego e salários, já que a taxa de câmbio esteve sob controle das autoridades monetárias no período em análise. A inclusão de time dummies nas estimações, no entanto, deve capturar, ao menos em parte, os eventuais efeitos da variação cambial no emprego e salários. Devido à relação teórica bi-causal entre salários e fluxo de comércio, em que menores salários aumentam as exportações, e maiores salários aumentam as importações, é possível que haja endogeneidade nos modelos estimados de salário. Como forma de remediar esse potencial problema, empregou-se o método de variáveis instrumentais. As variáveis instrumentais utilizadas foram taxa de câmbio setorial e preços industriais americanos.

Uma importante vantagem das variáveis de fluxo comercial sobre aquelas de política comercial é que elas são capazes de capturar todo o efeito do comércio exterior na alocação dos recursos, no sentido de que nelas estão intrinsecamente incorporados os efeitos da valorização ou desvalorização cambial, mudanças nas tarifas e remoção ou inclusão de proteção não-tarifária - variáveis não presentes nos modelos estimados, mas que afetam a decisão de importar e exportar. Pode ocorrer, por exemplo, que simultaneamente a uma redução das tarifas nominais haja desvalorização cambial, como ocorreu no México logo após a reforma da política comercial em meados dos anos 80. Nesse caso, o efeito da redução das tarifas pode ser anulado pela desvalorização cambial e nenhum impacto será observado nos fluxos comerciais, apesar da redução tarifária. No caso de proteção não-tarifária, considere que haja proibição da importação de um produto qualquer. Assim, mesmo que as tarifas sejam reduzidas, continuará não havendo qualquer importação. Dessa forma, parece-nos que variáveis de fluxo comercial são mais adequadas para analisar o caso do Brasil, em que mudanças nas políticas cambiais e de proteção não-tarifária foram a norma, e não a exceção, nas últimas décadas.

As indústrias examinadas no estudo são: minerais não metálicos, metalúrgica, mecânica, material elétrico e eletrônico, material de transportes, borracha, quí-

\footnotetext{
${ }^{6}$ Uma razão adicional é que as tarifas não são um bom indicador de mudanças alocativas, já que elas são mais adequadas para análises de equilíbrio parcial de mudanças na política comercial. Infelizmente, ainda não dispomos, para o Brasil, de variáveis relativas à proteção não tarifária ao nível da indústria. Essa variável é potencialmente importante para o caso brasileiro, em que utilizou-se intensamente, e por muitas décadas, várias medidas não tarifárias de proteção.
} 
mica, produtos e materiais plásticos, têxtil, vestuário, produtos alimentares, calçados, celulose, papel e gráfica, extrativa mineral, farmacêutica e perfumaria, madeira e mobiliário, petróleo e gás, refino de petróleo e indústrias diversas. Esse conjunto de indústrias e o período investigados resultam da compatibilização entre as fontes de informação empregadas. ${ }^{7} \mathrm{Na}$ medida em que as indústrias examinadas são do setor comercializável, pode-se esperar efeitos mais intensos da liberalização sobre as estruturas de emprego e salários, já que ali a competição internacional é mais elevada que no restante da economia. ${ }^{8}$

\section{Resultados}

\section{Estatísticas descritivas}

Antes de passar aos exercícios econométricos, examina-se a tabela 1, que apresenta as estatísticas descritivas das variáveis do modelo antes e depois da abertura. O desvio padrão da participação do emprego industrial aumentou de 3,9\% para $4,6 \%$ do primeiro para o segundo período (linha 1), o que sugere que teria havido mudança na estrutura do emprego após a liberalização comercial. Uma análise das taxas de crescimento ponto-a-ponto da participação do emprego industrial entre os anos de 1987 e 1998 também indica que teria havido realocação do trabalho, já que algumas indústrias ganharam enquanto outras perderam participação relativa no emprego. Os cinco setores que mais ganharam participação no emprego foram indústrias diversas, com crescimento de 40,4\%, alimentação, com 29,5\%, farmacêuticos e perfumaria, com 20,7\%, artigos de vestuário, com 18,2\%, e plásticos, com $15,4 \%$. Os cinco setores que mais perderam participação foram extrativa mineral, com crescimento de $-46,2 \%$, têxtil com $-42,7 \%$, elétrico e eletrônico, com $-38,5 \%$, petróleo e gás, com $-35,5 \%$, e indústria da borracha, com $-20,8 \%$. Não há um padrão tecnológico aparente na mudança do emprego industrial, uma vez que tanto indústrias trabalho-intensivas como capital-intensivas experimentaram crescimento e queda da participação no emprego.

O prêmio salarial inter-industrial controlado (linha 2) apresentou leve queda no nível e no desvio padrão após a abertura, sugerindo que a formação dos salários tornou-se mais competitiva. Uma vez que se omite dos dados as indústrias de

\footnotetext{
${ }^{7} \mathrm{~A}$ agregação de setores de atividade com os dados de comércio internacional não é plenamente compatível com aquela relacionada à PNAD. Para definir uma agregação que permitisse o cruzamento das diferentes fontes, baseamo-nos em IBGE (1997).

${ }^{8}$ Márquez e Pagés (1997) mostram que a liberalização comercial afetou mais o emprego e os salários da manufatura do que dos outros setores em países da América Latina.
} 
petróleo e gás e refino de petróleo - que são setores altamente concentrados, sob controle do Estado, e que foram pouco afetados pela abertura, o que lhes permite experimentar elevados prêmios salariais - a média de prêmio salarial cai para $4,2 \%$ antes da abertura, e para $4,5 \%$ após a abertura, níveis muito inferiores aos observados com aquelas indústrias. O desvio padrão, por sua vez, cai de 16,2\% para $14,4 \%$, respectivamente. As taxas de crescimento dos prêmios mudaram significantemente entre 1987 e 1998. Os setores que experimentaram as maiores quedas foram a indústria extrativa mineral, com $-82 \%$, indústrias diversas, com $-76 \%$, máquinas e tratores, com $-47 \%$, extração mineral, com $-44,5 \%$, e alimentos, com $-44 \%$. As indústrias que apresentaram maiores taxas positivas de crescimento dos prêmios foram a indústria da borracha, com 10\%, veículos e peças, com $13,2 \%$, calçados, com 25,4\%, farmacêutica e perfumaria, com $37,4 \%$, e celulose e papel, com $164 \%$.

As médias das tarifas efetivas e nominais (linhas 3 e 4) observaram substancial queda após 1992. A significativa redução do desvio padrão, por sua vez, mostra que a tarifa modal caiu para níveis muito inferiores aos prevalecentes antes da abertura. Os coeficientes de correlação dos vetores tarifários são positivos e elevados, sugerindo que a mudança na estrutura de proteção foi relativamente uniforme.

A penetração de importações média (linha 5) subiu de 11,4\% antes da abertura, para $18 \%$ pós-abertura, o que perfaz um aumento de $74 \%$. À exceção das indústrias de petróleo e gás e extrativa mineral, todas as demais indústrias experimentaram significativo crescimento da parcela importada no consumo aparente. Os coeficientes de correlação entre os vetores anuais de penetração de importação são elevados e positivos, o que sugere que a redução da proteção levou ao aumento das importações industriais de forma relativamente uniforme. As exceções são os anos de 1991 e 1998, em que os coeficientes de correlação calculados foram elevados, porém negativos. O ano de 1991 foi caracterizado por forte recessão e pela substancial redução das tarifas nominais, os quais teriam afetado de forma diferente as importações industriais. O ano de 1998 foi caracterizado por forte valorização cambial e pela expectativa de desvalorização cambial prevista pelos agentes econômicos ao longo de todo o ano, o que deve ter influenciado o regime das importações industriais.

A média de intensidade das exportações (linha 6) elevou de $13,4 \%$ para $16,9 \%$ após a abertura, perfazendo crescimento de $26 \%$, número bastante inferior ao observado na penetração de importações. O desvio padrão cresceu entre os dois períodos, indicando mudanças nas proporções exportadas ao nível da indústria. Apesar disso, o perfil das exportações industriais manteve-se relativamente uniforme, já que os coeficientes de correlação dos vetores anuais de intensidade de 
exportações são da ordem de 0,9 ou superior.

Tabela 1

Estatísticas descritivas (em \%)

\begin{tabular}{|c|c|c|c|c|c|c|}
\hline & $\begin{array}{l}\text { Todo o } \\
\text { período }\end{array}$ & & $\begin{array}{c}\text { Antes da } \\
\text { abertura } \\
(1987-1990)\end{array}$ & & $\begin{array}{c}\text { Depois da } \\
\text { abertura } \\
(1992-1998)\end{array}$ & \\
\hline & Média & $\begin{array}{l}\text { Desvio } \\
\text { padrão }\end{array}$ & Média & $\begin{array}{l}\text { Desvio } \\
\text { padrão }\end{array}$ & Média & $\begin{array}{l}\text { Desvio } \\
\text { padrão }\end{array}$ \\
\hline $\begin{array}{l}\text { Participação } \\
\text { no emprego }\end{array}$ & 5,26 & 4,37 & 5,26 & 3,93 & 5,26 & 4,65 \\
\hline $\begin{array}{l}\text { Prêmio salarial } \\
\text { inter-industrial } \\
\text { (controlado) }\end{array}$ & 9,00 & 20,02 & 9,16 & 21,32 & 9,00 & 19,27 \\
\hline Proteção efetiva & 33,51 & 3,34 & 55,5 & 38,11 & 18,82 & 18,72 \\
\hline Proteção nominal & 24,91 & 18,93 & 41,1 & 19,74 & 14,1 & 6,82 \\
\hline $\begin{array}{l}\text { Penetração de } \\
\text { importação }\end{array}$ & 15,31 & 38,18 & 11,37 & 25,76 & 17,94 & 44,50 \\
\hline $\begin{array}{l}\text { Intensidade de } \\
\text { exportação }\end{array}$ & 15,48 & 23,93 & 13,42 & 21,34 & 16,86 & 25,51 \\
\hline Número de anos $(\mathrm{T})$ & 10 & - & 4 & - & 6 & - \\
\hline $\begin{array}{l}\text { Número de } \\
\text { indústrias (n) }\end{array}$ & 19 & - & 19 & - & 19 & - \\
\hline Observações (N) & 190 & - & 76 & - & 114 & - \\
\hline
\end{tabular}

As tabelas 2 e 3 apresentam os coeficientes de correlação da participação no emprego industrial e dos prêmios salariais inter-industriais, respectivamente. Os números mostram que as estruturas de emprego e salários permaneceram surpreendentemente estáveis no período investigado. A implicação dessa estabilidade é que a abertura comercial teria tido modesto impacto na alocação setorial do emprego e nos salários relativos, e, portanto, nas estruturas de emprego e salário. ${ }^{9}$ A relativa estabilidade das estruturas de tarifas, penetração de importação e intensidade de exportação reforçam a expectativa de que as estruturas de emprego e salários teriam experimentado poucas mudanças após a abertura.

${ }^{9}$ Arbache et alii (2004a) encontram elevadíssima estabilidade dos vetores de prêmios salariais controlados ao nível industrial de 3 dígitos para o período 1981 a 1999, sugerindo que a estabilidade da estrutura salarial é definitivamente muito elevada no Brasil. 
Tabela 2

Coeficiente de correlação da participação no emprego industrial

\begin{tabular}{ccccccccccc}
\hline Ano & 1987 & 1988 & 1989 & 1990 & 1992 & 1993 & 1995 & 1996 & 1997 & 1998 \\
\hline 1987 & 1 & & & & & & & & & \\
1988 & 0,996 & 1 & & & & & & & & \\
1989 & 0,994 & 0,994 & 1 & & & & & & & \\
1990 & 0,993 & 0,993 & 0,997 & 1 & & & & & & \\
1992 & 0,973 & 0,968 & 0,969 & 0,976 & 1 & & & & \\
1993 & 0,973 & 0,969 & 0,974 & 0,978 & 0,994 & 1 & & & \\
1995 & 0,970 & 0,962 & 0,967 & 0,973 & 0,995 & 0,992 & 1 & & & \\
1996 & 0,970 & 0,961 & 0,966 & 0,972 & 0,993 & 0,992 & 0,997 & 1 & & \\
1997 & 0,963 & 0,952 & 0,955 & 0,962 & 0,992 & 0,988 & 0,997 & 0,997 & 1 & \\
1998 & 0,956 & 0,947 & 0,951 & 0,959 & 0,991 & 0,988 & 0,996 & 0,995 & 0,997 & 1 \\
\hline Nota: todos os coeficientes são significativos ao nível de 5\% de significância. N=19 &
\end{tabular}

Tabela 3

Coeficiente de correlação do prêmio salarial inter-industrial

\begin{tabular}{|c|c|c|c|c|c|c|c|c|c|c|}
\hline Ano & 1987 & 1988 & 1989 & 1990 & 1992 & 1993 & 1995 & 1996 & 1997 & 1998 \\
\hline 1987 & 1 & & & & & & & & & \\
\hline 1988 & 0,986 & 1 & & & & & & & & \\
\hline 1989 & 0,948 & 0,944 & 1 & & & & & & & \\
\hline 1990 & 0,91 & 0,928 & 0,951 & 1 & & & & & & \\
\hline 1992 & 0,948 & 0,957 & 0,923 & 0,914 & 1 & & & & & \\
\hline 1993 & 0,951 & 0,951 & 0,917 & 0,903 & 0,974 & 1 & & & & \\
\hline 1995 & 0,884 & 0,903 & 0,874 & 0,899 & 0,945 & 0,939 & 1 & & & \\
\hline 1996 & 0,831 & 0,828 & 0,843 & 0,834 & 0,904 & 0,911 & 0,961 & 1 & & \\
\hline 1997 & 0,921 & 0,932 & 0,886 & 0,897 & 0,968 & 0,951 & 0,969 & 0,924 & 1 & \\
\hline 1998 & 0,933 & 0,937 & 0,893 & 0,881 & 0,963 & 0,948 & 0,966 & 0,946 & 0,980 & 1 \\
\hline
\end{tabular}




\section{Resultados Econométricos}

As tabelas 4 e 5 apresentam os resultados dos modelos estimados tendo como variáveis dependentes a participação no emprego industrial e o prêmio salarial inter-industrial, respectivamente. A tabela 4a sugere que a redução das tarifas não teve efeito na estrutura de emprego, ou seja, a remoção de barreiras tarifárias não teria provocado mudanças nas importações a ponto de induzir a realocação do trabalho. Esse efeito pode estar associado à pouca adequação das tarifas para medir a realocação setorial de fatores de produção e mudanças nos preços relativos, tal como argumentado anteriormente. ${ }^{10}$

Tabela $4 \mathrm{a}$

Participação no emprego industrial

\begin{tabular}{|c|c|c|c|c|c|c|}
\hline & Modelo (1) & Modelo (2) & Modelo (3) & Modelo (4) & Modelo (5) & Modelo (6) \\
\hline Tarifa efetiva & $\begin{array}{c}0,002 \\
(0,009)\end{array}$ & & $\begin{array}{c}0,004 \\
(0,012)\end{array}$ & & $\begin{array}{l}-0,002 \\
(0,002)\end{array}$ & \\
\hline Tarifa nominal & & $\begin{array}{c}0,010 \\
(0,016)\end{array}$ & & $\begin{array}{c}0,026 \\
(0,027)\end{array}$ & & $\begin{array}{c}-0,008 \\
(0,008)\end{array}$ \\
\hline Time dummies & Não & Não & Sim & Sim & Sim & Sim \\
\hline Efeitos fixos & Não & Não & Não & Não & Sim & Sim \\
\hline $\mathrm{R}^{2}$ & 0,000 & 0,002 & 0,005 & 0,001 & 0,000 & 0,005 \\
\hline $\mathrm{N}$ & 190 & 190 & 190 & 190 & 190 & 190 \\
\hline
\end{tabular}

A tabela 4b mostra a relação entre participação no emprego e variáveis de fluxo comercial. Os modelos (1) e (3) sugerem associação negativa entre aumento da penetração das importações e emprego. A redução do emprego devido ao aumento das importações sugere que os consumidores teriam substituído consumo doméstico por consumo importado, provocando queda da demanda por trabalho nas indústrias mais afetadas pela competição externa. O modelo (5), no entanto, mostra que o efeito desaparece quando efeitos fixos são incluídos, o que sugere não ter havido mudança na estrutura de emprego. A intensidade de exportações, por seu turno, não afetou a estrutura de emprego.

A insensibilidade da estrutura do emprego à abertura sugere que as indústrias teriam sido similarmente afetadas pela competição externa. Algumas hipóteses

\footnotetext{
${ }^{10}$ Rossi e Ferreira (1999) encontram que variáveis de proteção tarifária têm impacto menor que as de fluxo comercial para explicar o efeito da abertura comercial sobre a produtividade setorial.
} 
poderiam explicar o fenômeno, como a que a abertura teria sido limitada, e, portanto, insuficiente para provocar mudanças substanciais na alocação de recursos, e/ou que o período de análise é insuficiente para capturar os efeitos da abertura sobre a alocação de fatores, os quais se verificariam a mais longo prazo.

Tabela $4 \mathrm{~b}$

Participação no emprego industrial

\begin{tabular}{|c|c|c|c|c|c|c|}
\hline & Modelo (1) & Modelo (2) & Modelo (3) & Modelo (4) & Modelo (5) & Modelo (6) \\
\hline $\begin{array}{l}\text { Penetração de } \\
\text { importações }\end{array}$ & $\begin{array}{c}-1,65^{*} \\
(0,826)\end{array}$ & & $\begin{array}{c}-1,70^{* *} \\
(0,859)\end{array}$ & & $\begin{array}{l}-0,025 \\
(0,197)\end{array}$ & \\
\hline $\begin{array}{l}\text { Intensidade } \\
\text { de exportações }\end{array}$ & & $\begin{array}{c}1,54 \\
(1,327)\end{array}$ & & $\begin{array}{c}1,55 \\
(1,366)\end{array}$ & & $\begin{array}{c}-1,70 \\
(1,233)\end{array}$ \\
\hline Time dummies & Não & Não & Sim & Sim & Sim & Sim \\
\hline Efeitos fixos & Não & Não & Não & Não & Sim & Sim \\
\hline $\mathrm{R}^{2}$ & 0,02 & 0,007 & 0,02 & 0,000 & 0,02 & 0,000 \\
\hline $\mathrm{N}$ & 190 & 190 & 190 & 190 & 190 & 190 \\
\hline
\end{tabular}

A tabela 5a apresenta os efeitos das tarifas sobre os prêmios salariais. Parece haver uma relação inversa, embora bastante pequena, entre tarifas e prêmios. Os resultados com (\#) resultam da retirada de outliers de tarifas efetivas, já que os modelos mostraram-se muito sensíveis à sua presença. ${ }^{11}$ Os coeficientes tornaramse não apenas estatisticamente significativos, mas, também, maiores quando comparados com os coeficientes estimados com toda a série, sugerindo que os outliers traziam efeitos indevidos às estimações. Uma possível interpretação da relação qualitativa identificada entre tarifas e prêmios salariais é que o aumento da competição internacional estaria afetando a eficiência e a produtividade de tal forma a elevar, e não a diminuir os prêmios, o que se daria através de salários de eficiência e/ou da adoção de métodos operacionais, gerenciais e tecnológicos mais avançados para fazer face ao aumento da competição externa no mercado local.

\footnotetext{
${ }^{11}$ Valores acima de $117 \%$ foram retirados da amostra.
} 
Tabela 5a

Prêmio salarial inter-industrial

\begin{tabular}{|c|c|c|c|c|c|c|}
\hline & Modelo (1) & Modelo (2) & Modelo (3) & Modelo (4) & Modelo (5) & Modelo (6) \\
\hline Tarifa efetiva & $\begin{array}{l}-0,000 \\
(0,000)\end{array}$ & & $\begin{array}{l}-0,000 \\
(0,000)\end{array}$ & & $\begin{array}{c}-0,000^{*} \\
(0,000)\end{array}$ & \\
\hline Tarifa efetiva(\#) & $\begin{array}{c}-0,001^{*} \\
(0,000)\end{array}$ & & $\begin{array}{c}-0,003^{*} \\
(0,000)\end{array}$ & & $\begin{array}{c}-0,001^{*} \\
(0,000)\end{array}$ & \\
\hline Tarifa nominal & & $\begin{array}{c}-0,002^{*} \\
(0,000)\end{array}$ & & $\begin{array}{c}-0,005^{*} \\
(0,001)\end{array}$ & & $\begin{array}{c}-0,001^{*} \\
(0,000)\end{array}$ \\
\hline Time dummies & Não & Não & Sim & Sim & Sim & Sim \\
\hline Efeitos fixos & Não & Não & Não & Não & Sim & Sim \\
\hline $\mathrm{R}^{2}$ & 0,000 & 0,04 & 0,002 & 0,106 & 0,001 & 0,108 \\
\hline $\mathrm{R}^{2}(\#)$ & 0,032 & 0,031 & 0,070 & 0,098 & 0,060 & 0,094 \\
\hline $\mathrm{N}$ & 190 & 190 & 190 & 190 & 190 & 190 \\
\hline $\mathrm{N}(\#)$ & 181 & 181 & 181 & 181 & 181 & 181 \\
\hline
\end{tabular}

Nota: $(*)$ estatisticamente significantes a 5\%. Erro padrão entre parênteses.

(\#) Foram apenas consideradas tarifas efetivas inferiores a $117 \%$.

A tabela 5b apresenta os resultados entre medidas de fluxo comercial e salários. Penetração de importações não parece ter tido qualquer efeito sobre a estrutura dos salários. O resultado é inesperado, pois poder-se-ia esperar que a maior competição tivesse afetado a formação dos salários, ou mesmo que tivesse reduzido ou eliminado os eventuais efeitos de rent-sharing.

Intensidade de exportações, por outro lado, parece ter tido substancial e robusto efeito sobre a estrutura salarial. Os sinais negativos sugerem que setores que experimentaram maior incremento de exportações experimentaram redução de salários relativos e vice-versa. A compressão dos salários das indústrias mais voltadas à exportação pode resultar do crescente aumento da competição entre países em desenvolvimento por mercados de commodities e produtos semi-acabados, tal como sugere a hipótese dos late-comer countries (Arbache, 2001). O aumento da competitividade internacional estaria, pois, associada, ao menos parcialmente, ao cortes de custos salariais. Em consonância com esse resultado está a não significância do coeficiente de intensidade de exportações no modelo de emprego, o qual sugere que as indústrias voltadas para o mercado externo estariam atendendo à maior demanda sem aumentar o emprego relativo, o que só é possível com maior produtividade do trabalho. Logo, parece que o setor exportador estaria 
reduzindo custos e elevando a produtividade para concorrer no mercado internacional. ${ }^{12}$

Tabela 5b

Prêmio salarial inter-industrial

\begin{tabular}{|c|c|c|c|c|c|c|}
\hline & Modelo (1) & Modelo (2) & Modelo (3) & Modelo (4) & Modelo (5) & Modelo (6) \\
\hline $\begin{array}{l}\text { Penetração } \\
\text { de importações }\end{array}$ & $\begin{array}{c}0,050 \\
(0,038)\end{array}$ & & $\begin{array}{c}0,052 \\
(0,039)\end{array}$ & & $\begin{array}{c}-0,014 \\
(0,015)\end{array}$ & \\
\hline $\begin{array}{l}\text { Intensidade } \\
\text { de exportações }\end{array}$ & & $\begin{array}{c}-0,130^{*} \\
(0,060)\end{array}$ & & $\begin{array}{c}-0,131 * \\
(0,062)\end{array}$ & & $\begin{array}{c}-0,321^{*} \\
(0,095)\end{array}$ \\
\hline Time dummies & Não & Não & Sim & Sim & Sim & Sim \\
\hline Efeitos fixos & Não & Não & Não & Não & Sim & Sim \\
\hline $\mathrm{R}^{2}$ & 0,009 & 0,024 & 0,011 & 0,025 & 0,000 & 0,025 \\
\hline $\mathrm{N}$ & 190 & 190 & 190 & 190 & 190 & 190 \\
\hline
\end{tabular}

Considerando-se a potencial endogeneidade entre salários e variáveis de fluxo comercial, procurou-se tratar do problema estimando-se modelos pelo método de variáveis instrumentais. Testaram-se dois possíveis instrumentos: câmbio setorial e índice de preços setoriais americanos. ${ }^{13}$ As correlações entre os regressores supostamente endógenos e câmbio setorial mostraram-se, no entanto, bastante baixas, bem como o poder explicativo do câmbio na equação reduzida. Dessa forma, apenas o segundo instrumento foi utilizado.

A tabela 5c apresenta os resultados das regressões, que confirmam, de um lado, que penetração de importação não tem efeito sobre a estrutura de salários; de outro lado, confirmam os resultados anteriores encontrados para intensidade de exportações. Note-se, no entanto, que o coeficiente do modelo de efeitos fixos tornou-se estatisticamente não significativo.

\footnotetext{
${ }^{12}$ Larre (1995) também encontra relação negativa entre intensidade de exportação e salários relativos para diversos países da OCDE. Ele emprega o mesmo argumento acima para interpretar os resultados.

${ }^{13}$ Os detalhes da construção da taxa de câmbio setorial podem ser obtidos por solicitação aos autores. Os preços industriais americanos foram gentilmente cedidos por Naércio Menezes.
} 
Tabela 5c

Prêmio salarial inter-industrial - Variável instrumental: preços industriais americanos

\begin{tabular}{|c|c|c|c|c|c|c|}
\hline & Modelo (1) & Modelo (2) & Modelo (3) & Modelo (4) & Modelo (5) & Modelo (6) \\
\hline $\begin{array}{l}\text { Penetração } \\
\text { de importações }\end{array}$ & $\begin{array}{l}-4,84 \\
(3,01)\end{array}$ & & $\begin{array}{c}0,151 \\
(0,390)\end{array}$ & & $\begin{array}{l}-0,50 \\
(0,95)\end{array}$ & \\
\hline $\begin{array}{l}\text { Intensidade } \\
\text { de exportações }\end{array}$ & & $\begin{array}{l}-2,41^{*} \\
(1,00)\end{array}$ & & $\begin{array}{l}-1,56^{*} \\
(0,624)\end{array}$ & & $\begin{array}{c}0,44 \\
(1,00)\end{array}$ \\
\hline Time dummies & Não & Não & Sim & Sim & Sim & Sim \\
\hline Efeitos fixos & Não & Não & Não & Não & Sim & Sim \\
\hline $\mathrm{R}^{2}$ & 0,009 & 0,042 & 0,015 & 0,049 & 0,097 & 0,046 \\
\hline $\mathrm{N}$ & 144 & 144 & 144 & 144 & 144 & 144 \\
\hline
\end{tabular}

Nota: $(*)$ estatisticamente significantes a $5 \%$.

Erro padrão entre parênteses.

\section{Conclusões}

Este artigo investigou se a liberalização comercial por que passou a economia brasileira entre o fim da década de 1980 e início da de 1990 afetou as estruturas de emprego e de salários inter-industriais. Ao contrário do que se poderia supor a partir dos teoremas de Heckscher e Ohlin e Stolper e Samuelson, a abertura teve efeitos negligenciáveis sobre as variáveis examinadas. A mais óbvia explicação para o fenômeno é a elevadíssima estabilidade temporal das estruturas de emprego e salário. Tal estabilidade estaria fortemente associada à estrutura de mercado e à distribuição de tecnologia entre setores, tal como sugerem Krueger e Summers (1987), Dickens e Katz (1987) e Katz e Summers (1989), e que seriam particularmente intensas para um país como o Brasil. Explicações complementares para o fenômeno seriam que: a abertura experimentada teria sido limitada e insuficiente para alterar a alocação de recursos e mudar os preços relativos; todos os setores teriam sido afetados similarmente pela abertura; e que o período de análise é insuficiente para capturar os efeitos da abertura na alocação de fatores e mudanças de preços relativos. Os resultados colocam em dúvida o argumento de que um processo de abertura provoca, necessariamente, realocação de fatores ao nível da indústria. Pode ser, no entanto, que a maior parte da realocação esteja ocorrendo entre firmas de uma mesma indústria, o que, infelizmente, não foi possível examinar neste artigo. 
Por fim, os resultados contribuem para explicar a estabilidade da distribuição de salários após a abertura (Green et alii, 2001) e as baixas taxas de crescimento das exportações na década de 1990.

\section{Referências}

Arbache, J. S. (1999). How do economic reforms affect the dispersion and structure of wages: The case of an industrializing country labor market. Buenos Aires: Anais do Twelfth World Congress of the International Economic Association.

Arbache, J. S. (2001). Liberalização comercial e mercado de trabalho no Brasil. In Lisboa, M. B. and Menezes-Filho, N. A. (Orgs.). Microeconomia e Sociedade No Brasil. Rio de Janeiro. Contra Capa e FGV/EPGE.

Arbache, J. S. (2002). Trade liberalization and labor markets in developing countries: Theory and evidence. In Levy, A. \& Faria, J. R., editors, Economic Growth, Inequality and Migration: National and International Perspectives. Edward Elgar, Cheltenham.

Arbache, J. S., Dickerson, A., \& Green, F. (2004a). Assessing the stability of interindustry wage differentials in the face of radical economic reforms. Economics Letters, 83:149-155.

Arbache, J. S., Dickerson, A., \& Green, F. (2004b). Trade liberalization and wages in developing countries. Economic Journal, 114(F73-F96).

Chamon, M. (1998). Rising wages and declining employment: The Brazilian manufacturing sector in the 90s'. Texto para Discussão No. 552, IPEA.

Currie, J. \& Harrison, A. (1997). Sharing costs: The impact of trade reform on capital and labor in Marroco. Journal of Labor Economics, 15:s44-s71.

Davis, D. R. (1996). Trade liberalization and income distribution. NBER Working Papers No. 5693.

Dickens, W. T. \& Katz, L. F. (1987). Inter-industry wage differences and industry characteristics. In Lang, K. \& Leonard, J., editors, Unemployment and the Structure of Labor Markets. Basil Blackwell, Oxford.

Freeman, R. B. \& Katz, L. F. (1991). Industrial wage and employment determination in an open economy. In Abowd, J. M. \& Freeman, R. B., editors, 
Immigration, Trade, and the Labor Market. University of Chicago Press, Chicago.

Gaston, N. \& Trefler, D. (1993). Tariffs, nontariff barriers to trade, and workers wages. In Bairam, E., editor, Studies in Labour Economics. Ashgate Publishing, London.

Green, F., Dickerson, A., \& Arbache, J. S. (2001). A picture of wage inequality and the allocation of labour through a period of trade liberalisation: The case of Brazil. World Development, 29:1923-1939.

Grossman, G. (1987). The employment and wage effects on import competition in the United States. Journal of International Economic Integration, 2:1-23.

Haguenauer, L., Markwald, R., \& Pourchet, H. (1998). Estimativas do valor da produção industrial e elaboração de coeficientes de exportação e importação da indústria brasileira. Texto para Discussão No. 563, IPEA.

Haisken-DeNew, J. P. \& Schmidt, C. M. (1997). Inter-industry and inter-region differentials: Mechanics and interpretation. Review of Economics and Statistics, 79:516-521.

Hanson, G. H. \& Harrison, A. (1999). Trade, technology, and wage inequality. Industrial and Labor Relations Review, 52:271-288.

Harrison, A. \& Hanson, G. H. (1999). Who gains from trade reform? Some remaining puzzles. Journal of Development Economics, 59:125-154.

Hay, D. (2001). The post 1990 Brazilian trade liberalization and the performance of large manufacturing firms: Productivity, market share and profits. Economic Journal, 473:620-641.

IBGE (1997). Sistema de Contas Nacionais: Brasil 1996, volume 2.

Katz, L. F. \& Summers, L. H. (1989). Industry rents: Evidence and implications. Brookings Papers on Economic Activity, Microeconomics, pages 209-275.

Krueger, A. B. \& Summers, L. H. (1987). Reflections on inter-industry wage structure. In Lang, K. \& Leonard, J., editors, Unemployment and the Structure of Labor Markets. Basil Blackwell, Oxford.

Krueger, A. B. \& Summers, L. H. (1988). Efficiency wages and the inter-industry wage structure. Econometrica, 56:259-193. 
Krueger, A. O. (1983). Trade and Employment in Developing Countries. Chicago University Press, Chicago.

Kume, H., Piani, G., \& Souza, C. F. (2003). A política brasileira de importação no período 1987-1998: Descrição e avaliação. In Corseuil, C. H. and Kume, H. (coord.). Brasília. MTE/IPEA.

Larre, B. (1995). The impact of trade on labour markets: An analysis by industry. The OECD Jobs Study Working Paper Series No. 6.

Li, H., Squire, L., \& Zou, H. (1998). Explaining international and intertemporal variations in income inequality. Economic Journal, 108:26-43.

Maia, K. (2001). Progresso tecnológico, qualificação da mão-de-obra e desemprego. Tese de Doutorado, Departamento de Economia, Universidade de Brasília.

Márquez, G. \& Pagés, C. (1997). Trade and employment: Evidence from Latin America and the Caribbean. Inter-American Development Bank, mimeo.

Menezes, N. \& Arbache, J. S. (2002). Trade liberalization, product and labor markets in Brazil. Universidade de São Paulo, mimeo.

Rama, M. (1994). The labor market and trade reform in manufacturing. In Connolly, M. \& de Melo, J., editors, The Effects of Protectionism on a Small Country. World Bank Regional and Sectoral Studies, Washington.

Revenga, A. (1992). Exporting jobs? The impact of import competition on employment and wages in U.S. manufacturing. Quarterly Journal of Economics, 107:255-284.

Revenga, A. (1997). Employment and wage effects of trade liberalization: The case of Mexican manufacturing. Journal of Labor Economics, 15:s20-s43.

Robbins, D. (1996). Stolper-Samuelson (lost) in the tropics? Trade liberalization and wages in Colombia: 1976-1994. Development Discussion Paper No. 563, Harvard Institute for International Development.

Rossi, J. L. \& Ferreira, P. C. (1999). Evolução da produtividade industrial brasileira e abertura comercial. Pesquisa e Planejamento Econômico, 29:1-36.

Salm, C., Sabóia, J., \& Carvalho, P. G. M. (1997). Produtividade na indústria brasileira: Questões metodológicas e novas evidências empíricas. Pesquisa e Planejamento Econômico, 27:377-396. 
Wood, A. (1999). Openness and wage inequality in developing countries: The Latin American challenge to East Asian conventional wisdom. In Baldwin, R. E., Cohen, D., Sapir, A., \& Venables, A., editors, Market Integration, Regionalism and the Global Economy. Cambridge University Press, Cambridge. 